\author{
Military Technical College \\ Kobry El-Kobbah, \\ Cairo, Egypt
}

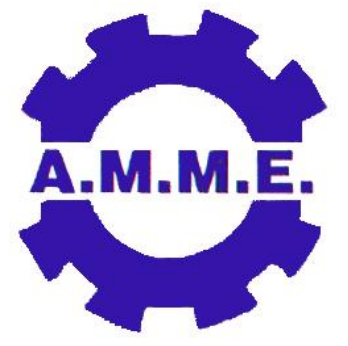

14th International Conference on

Applied Mechanics and

Mechanical Engineering.

\title{
A Study of High-Strength Borosilicate Glass by Crystallization and Ion Exchange for Bulletproof Materials
}

\author{
By \\ Gyu-In Shim* Jaemin Lim* $\quad$ Se-Young Choi*
}

\begin{abstract}
:
For application in light-weight bulletproof glass, the borosilicate glass was strengthened by ion exchange and crystallization. Basically, the mechanical properties of borosilicate glass were better than soda-lime-silicate (SLS) glass. Properties of ion exchanged glass heated at different conditions were measured. The Vickers hardness, fracture toughness and bending strength of ion exchanged samples were $821.8 \mathrm{H}_{\mathrm{v}}, 1.3404 \mathrm{MPa} \cdot \mathrm{m}^{\mathrm{T} / 2}$, and $953 \mathrm{MPa}$, which is about $120 \%, 180 \%$, and $450 \%$ higher than parent borosilicate glass, respectively. The borosilicate glass was heated by 2 -step crystallization. As a result, the Vickers hardness, fracture toughness and bending strength of crystallized samples were $735.7 \mathrm{H}_{\mathrm{v}}, 1.0779 \mathrm{MPa} \cdot \mathrm{m}^{1 / 2}$, and $493 \mathrm{MPa}$, which is about $17 \%, 45 \%$, and $149 \%$ higher than parent borosilicate glass, respectively. The results prove that light-weight bullet proof can be fabricated by ion exchange technique of borosilicate glass. The mechanical properties of borosilicate glass were increasing with additions of $\mathrm{ZrO}_{2}$ (until 7.5 wt. \%). Transmittance of ion exchanged and crystallized borosilicate glasses were decreased slightly at the visible range.
\end{abstract}

\section{Keywords:}

Borosilicate glass, crystallization, ion exchange, bulletproof 
* School of New Materials Science and Engineering, Yonsei University, Seoul, Korea

Recently, many researchers are carrying out over the application of the transparent bulletproof glass to enhance of mechanical properties. Borosilicate glasses generally have excellent mechanical properties, but poor producing [1]. Thus, addition of $\mathrm{ZrO}_{2}$ at various weight percent on borosilicate glass was confirmed thermal and mechanical properties. Pure zirconia exists in three crystal phases at different temperatures [2,3]. At very high temperatures (over $2370^{\circ} \mathrm{C}$ ) the material has a cubic structure. At intermediate temperatures $\left(1170\right.$ to $2370^{\circ} \mathrm{C}$ ) it has a tetragonal structure. At low temperatures (below $1170^{\circ} \mathrm{C}$ ) the material transforms to the monoclinic structure. The compositions of the borosilicate glass prepared are given in table 1. The hardness, fracture toughness, and bending strength of parent borosilicate glass were about $630 \mathrm{H}_{\mathrm{v}}, 0.7429 \mathrm{MPa} \cdot \mathrm{m}^{1 / 2}$, and $198 \mathrm{MPa}$, respectively. For application of transparent bulletproof materials, borosilicate glass was heated by 2 -step crystallization [4,5] and ion exchange by employing screen printing technique in $\mathrm{KNO}_{3}$ powder.

\section{Experimental procedures:}

Borosilicate glass was prepared in the composition of $81 \% \mathrm{SiO}_{2}, 4 \% \mathrm{Na}_{2} \mathrm{O}, 2 \% \mathrm{Al}_{2} \mathrm{O}_{3}$, $13.0 \% \mathrm{~B}_{2} \mathrm{O}_{3}$. For measurement of $\mathrm{T}_{\mathrm{g}}, \mathrm{T}_{\mathrm{c}(\max )}$, measured by differential thermal analysis (TG/DTA-92, Setaram, France). DTA run was performed for borosilicate glass powder by $10 \mathrm{~K} / \mathrm{min}$ as heating rate. The batches were melted in a Super Khantal Furnace (Lindberg Blue M, USA) at $1650{ }^{\circ} \mathrm{C}$ for $6 \mathrm{hr}$ using a Pt-Rd crucible. Borosilicate glasses were heated at $10 \mathrm{~K} / \mathrm{min}$ to the nucleation temperature between $520 \sim 560^{\circ} \mathrm{C}$, (intervals of $10 \mathrm{~K})$, then crystal growth was fixed at $650{ }^{\circ} \mathrm{C}(1 \mathrm{hr})$.

Table (1): Composition of the crystallized borosilicate glass (mol \%)

\begin{tabular}{|c|c|c|c|c|c|}
\hline Specimen & $\mathbf{S i O}_{\mathbf{2}}$ & $\mathbf{A l}_{\mathbf{2}} \mathbf{O}_{\mathbf{3}}$ & $\mathbf{B}_{\mathbf{2}} \mathbf{O}_{\mathbf{3}}$ & $\mathbf{N a}_{\mathbf{2}} \mathbf{O}$ & $\begin{array}{c}\mathbf{Z r O}_{\mathbf{2}} \\
\text { (wt. \%) }\end{array}$ \\
\hline $\mathrm{N}$ & 81 & 2 & 13 & 4 & 0 \\
\hline $\mathrm{NZ1}$ & 81 & 2 & 13 & 4 & 2.5 \\
\hline $\mathrm{NZ2}$ & 81 & 2 & 13 & 4 & 5.0 \\
\hline $\mathrm{NZ3}$ & 81 & 2 & 13 & 4 & 7.5 \\
\hline $\mathrm{NZ4}$ & 81 & 2 & 13 & 4 & 10.0 \\
\hline
\end{tabular}

The crystallized glasses were determined the morphology and composition of the crystallized phases using a scanning electron microscope (SEM, Hitachi S-3000M, Japan) and an energy dispersive X-ray spectrometer (EDX, Horiba EMAX, Japan).

Table (2): Composition of the ion exchanged borosilicate glass (mol \%)

\begin{tabular}{|c|c|c|c|c|c|}
\hline Specimen & $\mathrm{SiO}_{2}$ & $\mathrm{Al}_{2} \mathrm{O}_{3}$ & $\mathrm{~B}_{2} \mathrm{O}_{3}$ & $\mathrm{Na}_{2} \mathrm{O}$ & $\begin{array}{c}\mathrm{ZrO}_{2} \\
\text { (wt. \%) }\end{array}$ \\
\hline $\mathrm{N} 4$ & 81 & 2 & 13 & 4 & 0 \\
\hline
\end{tabular}




\begin{tabular}{|c|c|c|c|c|c|}
\hline N6 & 79 & 2 & 13 & 6 & 0 \\
\hline N8 & 77 & 2 & 13 & 8 & 0 \\
\hline N4Z4 & 81 & 2 & 13 & 4 & 4 \\
\hline N6Z4 & 79 & 2 & 13 & 6 & 4 \\
\hline N8Z4 & 77 & 2 & 13 & 8 & 4 \\
\hline
\end{tabular}

Properties of ion exchanged glass heated at different conditions (temperature, time) were examined. The $\mathrm{K}^{+}-\mathrm{Na}^{+}$ion exchange takes place at the glass surface and creates compressed stress which raise the mechanical strength of the glass. For all heat treated samples were excuted by X-ray diffraction (D/max III, Rigaku, Japan) using Ni-filtered $\mathrm{CuK}_{\alpha}$ radiation. Hardness and fracture toughness were measured using Vickers Microhardness Tester (MXD-CX3E, Matsuzawa, Japan). More than 10 indentations were made for each specimen with a 10 second loading time at a maximum load of $500 \mathrm{gf}$. The Vickers hardness was calculated from:

$H_{V}=0.4636 \cdot\left(\frac{P}{a^{2}}\right)$

where $\mathrm{P}$ is the load of indentation, $a$ is the radius of indentation. The fracture toughness was calculated from:

$K_{I C} \cdot \Phi / H_{V} \cdot a^{\frac{1}{2}}=0.15 \cdot K \cdot(c / a)^{-\frac{3}{2}}$

where $H_{v}$ is Vickers hardness, $\Phi$ is the restraint constant $(=3)$, and $a$ is the radius of indentation, $\mathrm{K}$ is a constant $(=3.2)$, and $\mathrm{c}$ is crack length.

$\sigma=3 \cdot P \cdot L / 2 \cdot w \cdot t^{2}$

where $P$ is maxium load, $L$ is outside the interval, $w$ is width, $t$ is thickness. For measurement of the mechanical strength, 3-point bending strength was employed to the bar type specimens using a Universal Testing Machine (H10K-C, Hounsfield, U.K.). To measure 3-point bending strength glass bars with diameter of $3 \times 4 \times 36 \mathrm{~mm}^{3}$ were cut out from borosilicate glasses and polished (\# $1000 \sim 2000$ ). The $\mathrm{KNO}_{3}$ powder (Ducsan, Extra pure, Korea) was prepared for ion exchanged. The depth profile of $\mathrm{Na}^{+}$and $\mathrm{K}^{+}$was observed Electron Probe Micro Analyzer (EPMA, JXA-8900R, JEOL, Japan). Transmittance was measured using UV/VIS/NIR Spectrometer (Jasco, V-570, Japan). The scan speed and range of wavelength were $400 \mathrm{~nm} / \mathrm{min}$, in the range of $200 \sim 800 \mathrm{~nm}$.

\section{Results and discussion:}

Fig. 1 shows that the glass transition temperature $\left(T_{g}\right)$ and crystallization temperature $\left(T_{c}\right.$, max) was $510 \sim 530{ }^{\circ} \mathrm{C}, 650 \sim 670{ }^{\circ} \mathrm{C}$. Thus, the glass specimen was nucleated at $10{ }^{\circ} \mathrm{C} / \mathrm{min}$ to the temperature range of $520 \sim 560{ }^{\circ} \mathrm{C}$ with intervals of $10{ }^{\circ} \mathrm{C}$ for $2 \mathrm{hr}$, and then crystallized at $650{ }^{\circ} \mathrm{C}$ for $1 \mathrm{hr}$. Fig. 1 shows the DTA traces for the borosilicate glass with $\mathrm{ZrO}_{2}$ (NZ1 : 2.5 wt. \%, NZ3: 7.5 wt. \%). Also give the evidence that $\mathrm{ZrO}_{2}$ promotes the crystallization of albite $\left(\mathrm{NaAlSi}_{3} \mathrm{O}_{8}\right)$. Albite is a plagioclase feldspar mineral and crystallizes with triclinic pinacoidal forms. As such it represents a plagioclase with less than $10 \%$ anorthite content. 
(a)

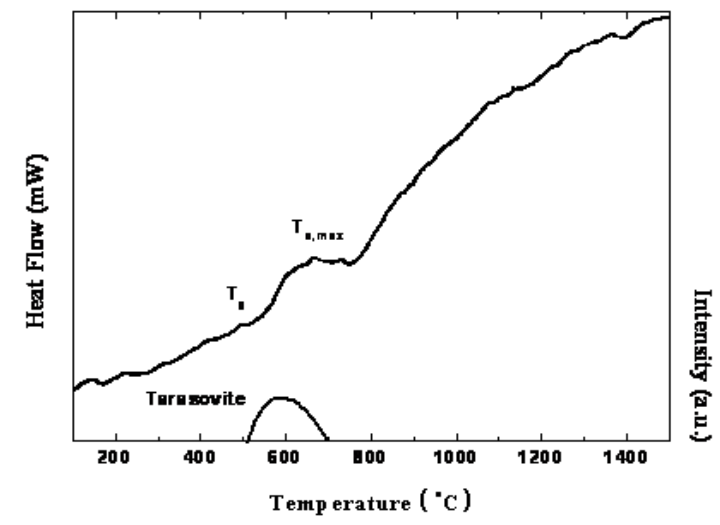

(b)

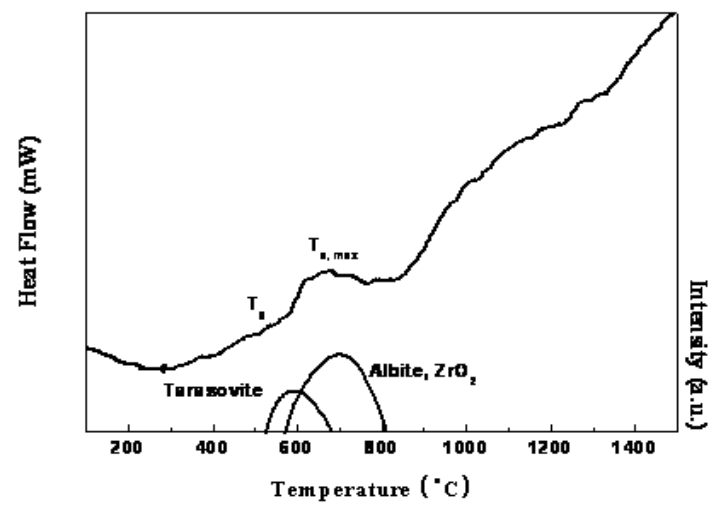

Figure (1): DTA curve of the parent borosilicate glass at $10 \mathrm{~K} / \mathrm{min}$ heating rate. The figure also shows the occurring phase. (a) N composition, (b) NZ3 composition

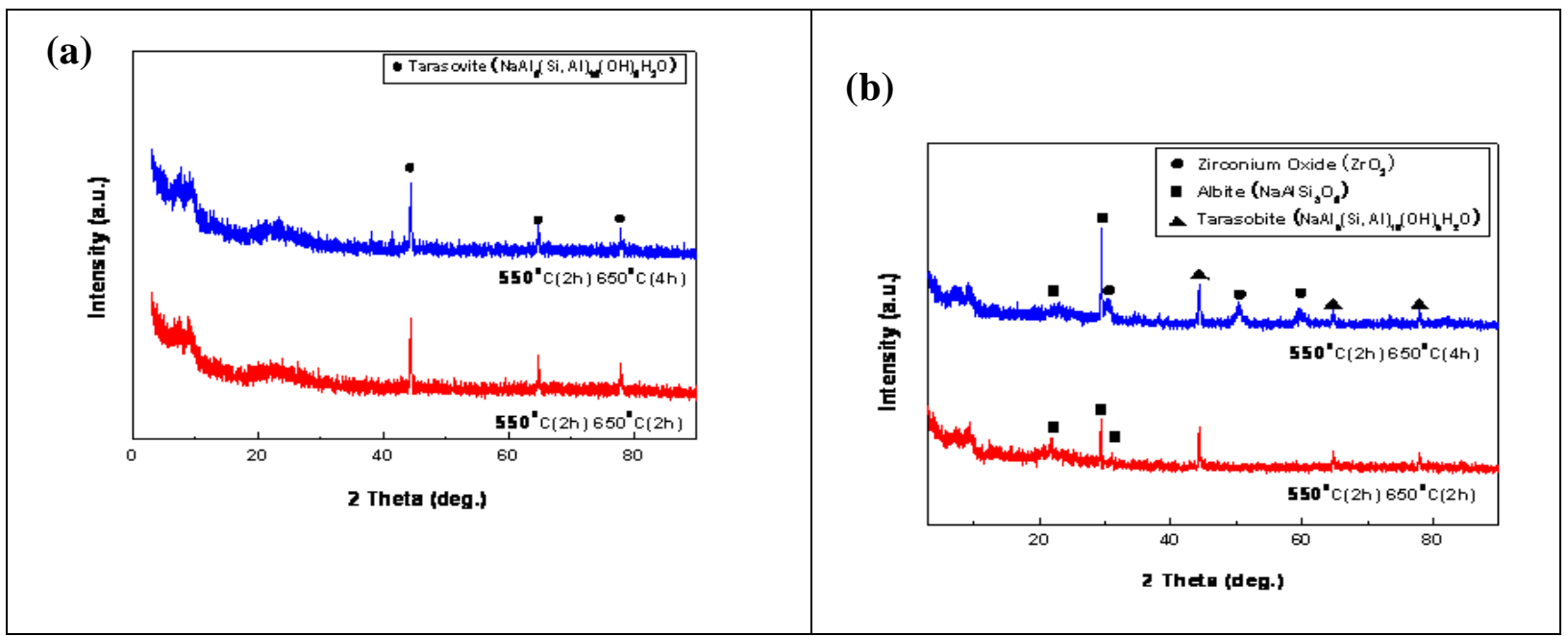

Figure (2): XRD patterns of parent and crystallized borosilicate glass. (a) N composition

(b) N3 composition

It is found from the XRD data in Fig. 2(b) that precipitations of tarasovite, albite, $\mathrm{ZrO}_{2}$ are observed. It means that the addition of $\mathrm{ZrO}_{2}$ increased the albite phase. Fig. 3 shows that the crystallized phase additional $\mathrm{ZrO}_{2}(\mathrm{c} \sim \mathrm{f})$ and without $\mathrm{ZrO}_{2}(\mathrm{a}, \mathrm{b})$. Fig. 2, 3 give the evidence that $\mathrm{ZrO}_{2}$ promotes the crystallization of albite and simultaneously suppresses the precipitation of $\mathrm{ZrO}_{2}$ phase. 


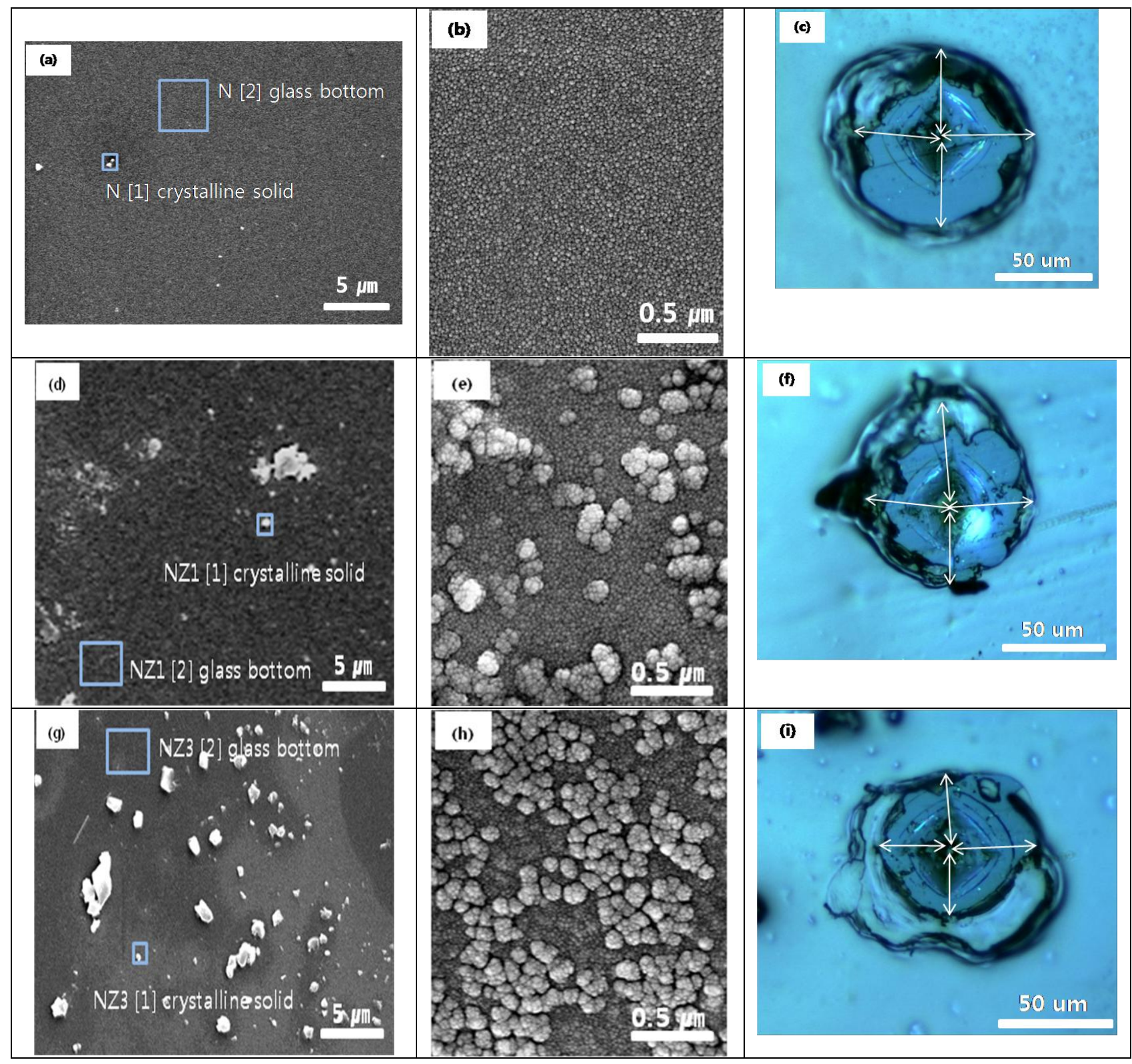

Figure (3): SEM image of nucleated borosilicate glass at $550{ }^{\circ} \mathrm{C}$ for $2 \mathrm{hr}$ (crystal growth at $650^{\circ} \mathrm{C}, 4 \mathrm{hr}$ ). (a), (b) N, (d), (e) NZ1, and (g), (h) NZ3 composition. Crack length of crystallized glass was (c), (f), and (i): 28.7, 27.0, $26.3 \mu \mathrm{m}$

Table (3): Compositions of each phase in crystallized borosilicate glass obtained by EDX (wt. \%)

\begin{tabular}{|c|r|r|r|r|r|r|}
\hline \hline $\begin{array}{l}\text { Compoistion } \\
\text { Element }\end{array}$ & N [1] & N [2] & NZ1 [1] & NZ1 [2] & NZ3 [1] & NZ3 [2] \\
\hline $\mathrm{O}$ & 42.25 & 42.63 & 55.93 & 53.59 & 26.10 & 24.33 \\
\hline $\mathrm{Na}$ & 3.47 & 4.29 & 3.24 & 6.95 & 2.08 & 7.96 \\
\hline $\mathrm{Al}$ & 1.94 & 2.00 & 1.44 & 4.17 & 1.74 & 7.53 \\
\hline $\mathrm{Si}$ & 52.34 & 51.08 & 30.30 & 27.75 & 41.96 & 36.48 \\
\hline $\mathrm{Zr}$ & - & - & 9.08 & 7.54 & 28.12 & 23.68 \\
\hline Totals & 100 & 100 & 100 & 100 & 100 & 100 \\
\hline
\end{tabular}


Such a increase in the additions of $\mathrm{ZrO}_{2}$ (until 7.5g) leads to a increase in the strength to $493 \mathrm{MPa}$, which is about $149 \%$ higher than parent borosilicate glass. The crystal size of $\mathrm{N}$, NZ1, NZ3 were about $28 \mathrm{~nm}$.

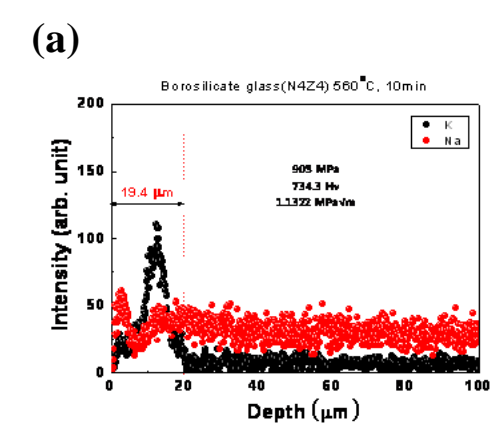

(b)

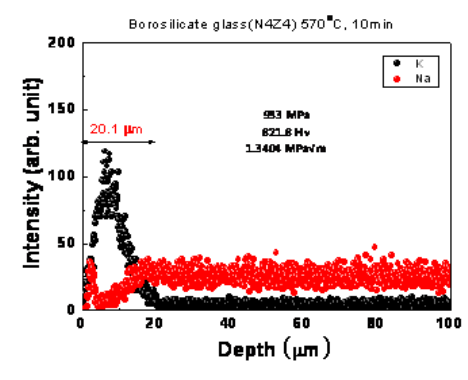

(c)

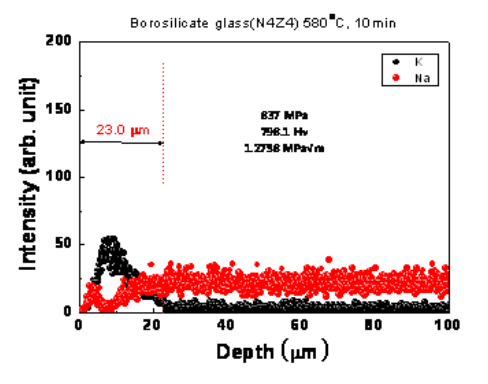

Figure (4): EPMA line profile of ion exchanged borosilicate glass by $\mathrm{KNO}_{3}$ powder (a) $560{ }^{\circ} \mathrm{C}$, (b) $570{ }^{\circ} \mathrm{C}$, and (c) $580{ }^{\circ} \mathrm{C}$ for $10 \mathrm{~min}$

Fig. 4 shows that EPMA line profile for the ion exchanged borosilicate glass was treated in $\mathrm{KNO}_{3}$ powder containing different temperature for $10 \mathrm{~min}$. In this process, $\mathrm{K}^{+}, \mathrm{Na}^{+}$ion exchange takes place at the glass surface and create a compressed stress which raise to the mechanical strength of the glass. With the increasing heat-treatment temperature from $560{ }^{\circ} \mathrm{C}$ to $580{ }^{\circ} \mathrm{C}$, the depth profile was increasing from $19.4 \mu \mathrm{m}$ to $23.0 \mu \mathrm{m}$, but mechanical properties were reduced. Fig. 5 shows the EPMA of the ion exchanged at various time. With the increasing heat-treatment time from $0 \mathrm{~min}$ to $20 \mathrm{~min}$, the depth profile was increasing from 17.1 um to 29.4 um, but mechanical properties were decreased, too. It was also found out that excessive heat treatment brings about stress relaxation.

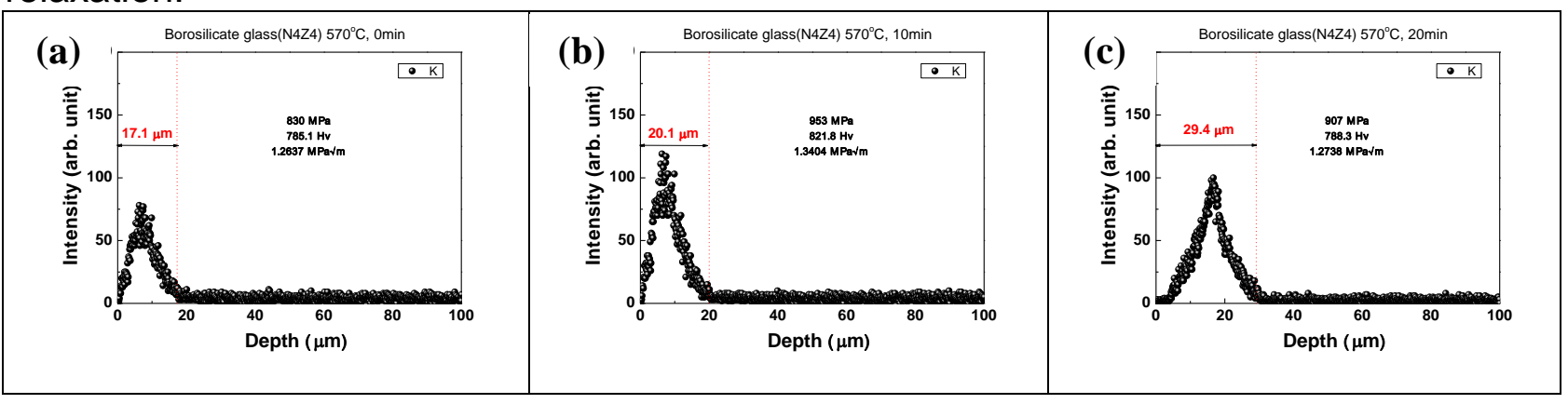

Figure (5): EPMA line profile of ion exchanged borosilicate glass by $\mathrm{KNO}_{3}$ powder at $570{ }^{\circ} \mathrm{C}$ for (a) $10 \mathrm{~min}$, (b) $20 \mathrm{~min}$, and (c) $30 \mathrm{~min}$

Therefore, we have to find the best conditions of ion exchange according to the temperature and time. Fig. 6, 7 shows that mechanical properties of crystallized and ion exchanged borosilicate glass. 


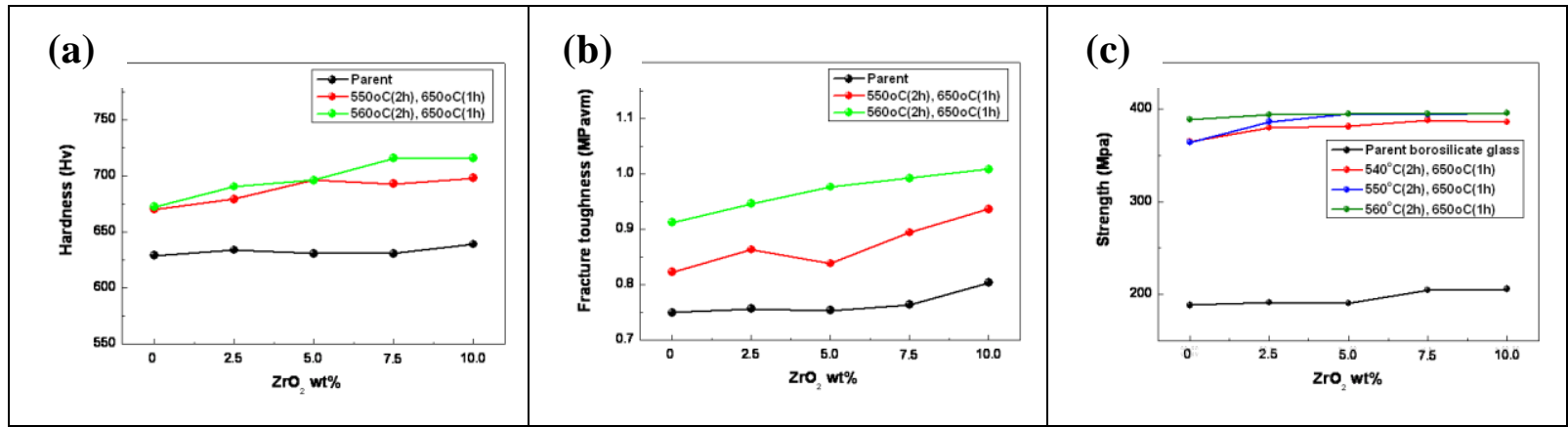

Figure (6): Hardness, Fracture toughness, and Strength of crystallized borosilicate glass at various wt\% of $\mathrm{ZrO}_{2}$ (crystal growth at $650{ }^{\circ} \mathrm{C}$ for $1 \mathrm{hr}$ )
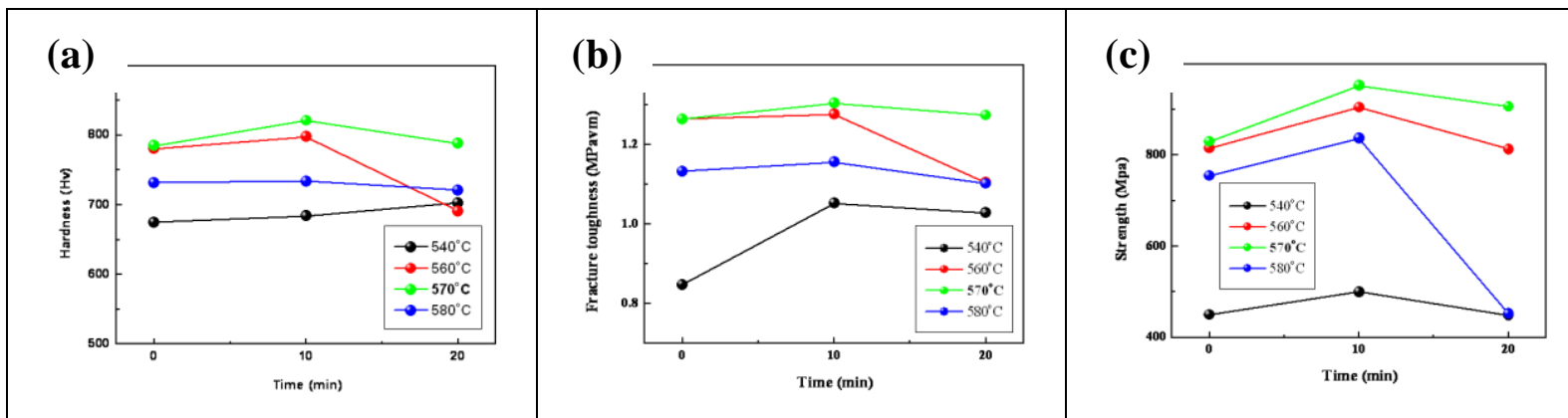

Figure (7): Hardness, Fracture toughness, and Strength of ion exchanged borosilicate glass at various time, temperature

Table (4): Mechanical properties of ion exchanged borosilicate glass at various time, temperature (composition : N4Z4)

\begin{tabular}{|c|c|c|c|c|}
\hline & $\begin{array}{c}\text { Time } \\
(\mathbf{m i n})\end{array}$ & $\begin{array}{c}\text { Hardness } \\
\left(\mathbf{H}_{\mathbf{v}}\right)\end{array}$ & $\begin{array}{c}\text { Fracture Toughness } \\
\left(\mathbf{M P a} \cdot \mathbf{m}^{\mathbf{1 / 2}}\right)\end{array}$ & $\begin{array}{c}\text { Strength } \\
(\mathbf{M P a})\end{array}$ \\
\hline \hline Parent glass & - & 685 & 0.7545 & 210 \\
\hline $\begin{array}{c}\text { lon exchanged } \\
\text { borosilicate } \\
\text { glass }\end{array}$ & 0 & 785 & 1.2637 & 830 \\
\cline { 2 - 5 } & 10 & 821 & 1.3040 & 953 \\
\cline { 2 - 5 } & 20 & 788 & 1.2738 & 907 \\
\hline
\end{tabular}

Table (5): Mechanical properties of crystallized borosilicate glass at various time, temperature $\left(550{ }^{\circ} \mathrm{C}\right.$ for $2 \mathrm{hr}, 650{ }^{\circ} \mathrm{C}$ for $4 \mathrm{hr}$ )

\begin{tabular}{|c|c|c|c|c|}
\hline & $\begin{array}{c}\mathbf{Z r O}_{\mathbf{2}} \\
(\mathbf{w t} . \%)\end{array}$ & $\begin{array}{c}\text { Hardness } \\
\left(\mathbf{H}_{\mathbf{v}}\right)\end{array}$ & $\begin{array}{c}\text { Fracture } \\
\text { Toughness } \\
\left(\mathbf{M P a} \cdot \mathbf{m}^{\mathbf{1 / 2}}\right)\end{array}$ & $\begin{array}{c}\text { Strength } \\
(\mathbf{M P a})\end{array}$ \\
\hline \hline Parent glass & - & 630 & 0.7429 & 198.00 \\
\hline \multirow{3}{*}{$\begin{array}{c}\text { Crystallized } \\
\text { borosilicate glass }\end{array}$} & 0 & 702 & 0.9808 & 374.64 \\
\cline { 2 - 5 } & 2.5 & 708 & 1.0050 & 397.67 \\
\cline { 2 - 5 } & 5.0 & 714 & 1.0579 & 443.26 \\
\cline { 2 - 5 } & 7.5 & 736 & 1.0779 & 493.37 \\
\hline
\end{tabular}




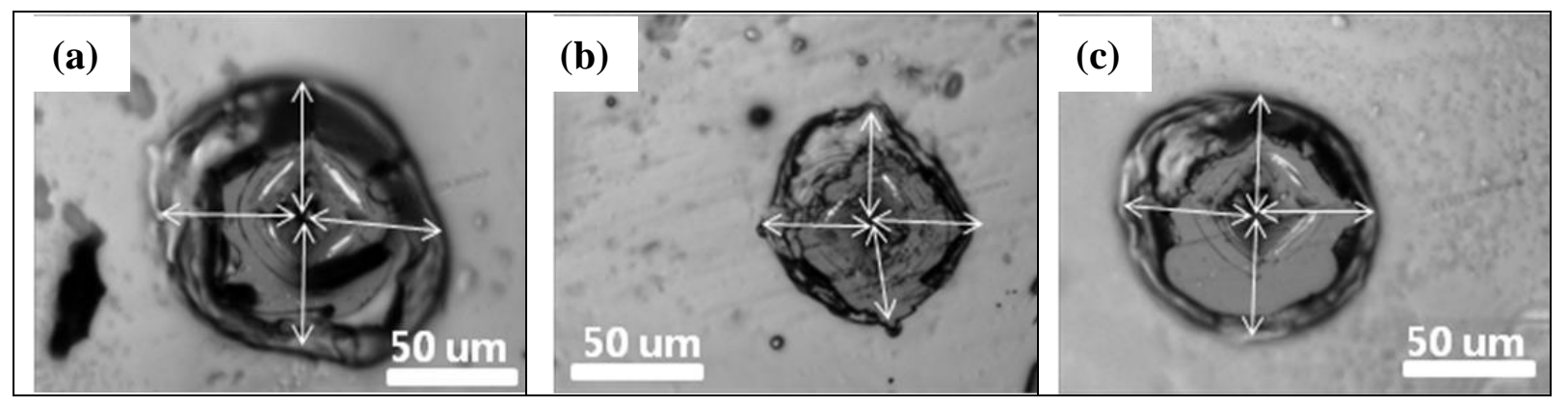

Figure (8): Optical microscope image of ion exchanged borosilicate glass at $570^{\circ} \mathrm{C}$ for (a) $0 \mathrm{~min},(\mathrm{~b}) 10 \mathrm{~min}$, and (c) $20 \mathrm{~min}$

The Vickers hardness, fracture toughness and bending strength of crystallized samples were $735.7 \mathrm{H}_{\mathrm{v}}, 1.0779 \mathrm{MPa} \cdot \mathrm{m}^{1 / 2}$, and $493 \mathrm{MPa}$, which is about $17 \%, 45 \%$, and $149 \%$ higher than parent borosilicate glass, respectively. The toughness of a material is the maximum amount of energy it can absorb before fracturing, which is different than the amount of force that can be applied. The Vickers hardness, fracture toughness and bending strength of ion exchanged samples were $821.8 \mathrm{H}_{\mathrm{v}}, 1.3404 \mathrm{MPa} \cdot \mathrm{m}^{1 / 2}$, and 953 $\mathrm{MPa}$, which is about $120 \%, 180 \%$, and $450 \%$ higher than parent borosilicate glass, respectively. Transmittance of ion exchanged and crystallized borosilicate glass was decreased slightly. The visible transmittance decreases with increasing crystal size. It is evident that the gradual decrease of visible transmittance is due to light scattering from the crystal phase particles. Scattering increases with increasing crystal size. As a result, the transmittance of crystallized glass was increasing with decreasing crystal growth time.

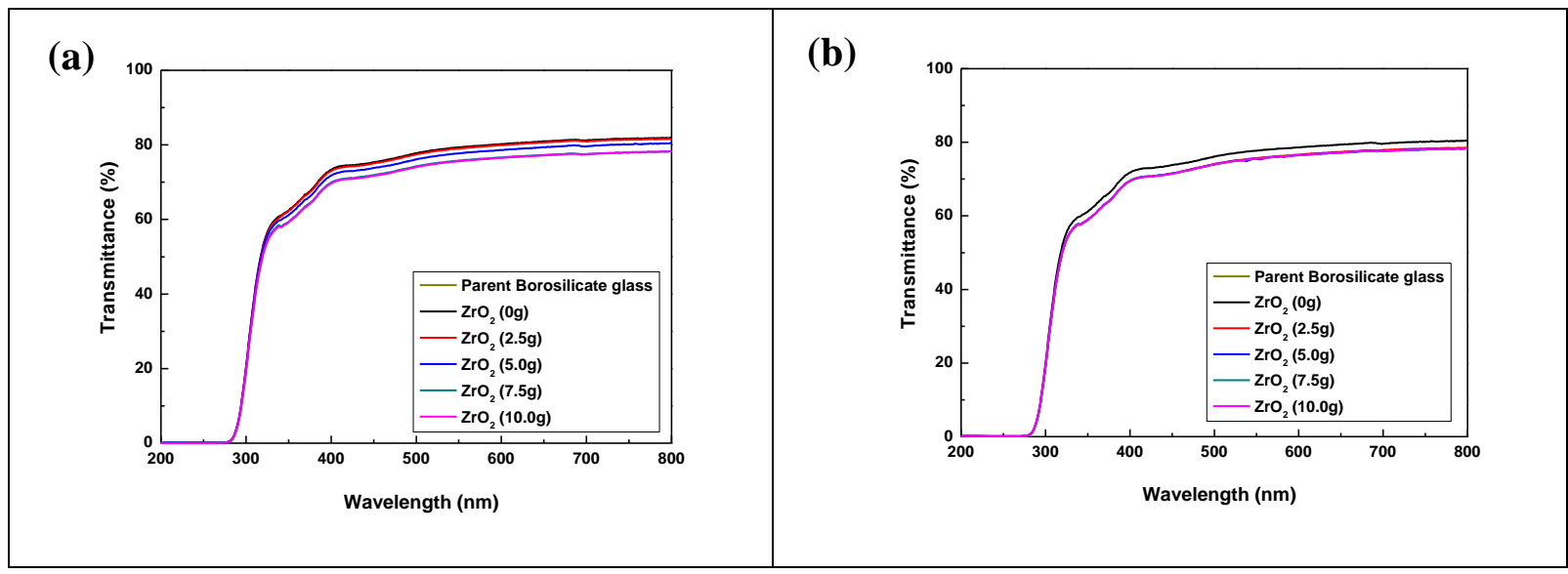

Figure (9): Transmittance of crystallized and ion exchanged borosilicate glass.

Crystallization at (a) $550^{\circ} \mathrm{C}$ for $2 \mathrm{hr}, 650^{\circ} \mathrm{C}$ for $2 \mathrm{hr}$, (b) $550^{\circ} \mathrm{C}$ for $2 \mathrm{hs}, 650^{\circ} \mathrm{C}$ for $4 \mathrm{hs}$

\section{Conclusions:}

For application in light-weight bulletproof glass, borosilicate glass was strengthened by crystallization and ion exchange. Also give the evidence that $\mathrm{ZrO}_{2}$ promotes the crystallization of albite $\left(\mathrm{NaAlSi}_{3} \mathrm{O}_{8}\right)$. Properties of crystallized and ion exchanged glass heated at different conditions were examined. As a result, the Vickers hardness, fracture toughness and bending strength of crystallized samples were $735.7 \mathrm{H}_{\mathrm{v}}, 1.0779 \mathrm{MPa} \cdot \mathrm{m}^{1 / 2}$, and $493 \mathrm{MPa}$, which is about $17 \%, 45 \%$, and $149 \%$ higher than parent borosilicate glass, 
respectively. The Vickers hardness, fracture toughness and bending strength of ion exchanged samples were $821.8 \mathrm{H}_{\mathrm{v}}, 1.3404 \mathrm{MPa} \cdot \mathrm{m}^{1 / 2}$, and $953 \mathrm{MPa}$, which is about $120 \%$, $180 \%$, and $450 \%$ higher than parent borosilicate glass, respectively. It is found out that $\mathrm{ZrO}_{2}$ promotes the crystallization of albite phase. Transmittance of ion exchanged and crystallized glass were decreased slightly at visible range. A transparent bulletproof material of borosilicate glass has been ballistically tested after impacting by $5.45 \mathrm{~mm}$ AK74 steel core projectiles at distance of 50 meters. The thickness of bulletproof material was about $30 \mathrm{~mm}$ (Korea Military Academy). It can be expected of transparent bulletproof materials in more light-weight and thinner (over 10 15\%) by ion exchange and crystallization.

\section{Acknowledgements:}

This work is supported by the Defence Nano Technology Application Center

\section{References:}

[1] M. Suszy, L. Krajczyk and Z. Mazurkiewicz, TEM studies of silver nanoparticles in phase-separated soda lime silicate glasses, Materials Chemistry and Physsics, Vol. 81, P. 404-406, 2003.

[2] M. Roskosz, M. J. Toplis and P. Richet, Kinetic vs. thermodynamic control of crystal nucleation and growth in molten silicates, Journal of Non-Crystalline Solid, Vol. 352, P. 180-184, 2006.

[3] A. Abd El-Moneim, Quantitative analysis of elastic moduli and structure of B2O3$\mathrm{SiO} 2$ and Na2O-B2O3-SiO2 glasses, Physica B, Vol. 325, P. 319-332, 2003.

[4] S. B. Sohn and S. Y. Choi, Crystallization behavior in the glass system $\mathrm{MgO}-\mathrm{Al}_{2} \mathrm{O}_{3^{-}}$ $\mathrm{SiO}_{2}$ :influence of $\mathrm{CeO}_{2}$ addition, Journal of Non-Crystalline Solid, Vol. 282, P. 221227, 2001.

[5] S. B. Sohn, Y. K. Lee, S. Y. Choi, Controlled crystallization and characterization of cordierite glass-ceramics for magnetic memory disk substrate, Journal of Materials Science, Vol. 35, P. 4815-4821, 2000.

[6] V. P. Pukh, L. G. Baikova, M. F. Kireenko, L. V. Tikhonova, T. P. Kazannikova, and A. B. Sinani, Atomic Structure and Strength of Inorganic Glasses, Physis of the Solid State, Vol. 47, No. 5, P. 876-881, 2005.

[7] Z. Xiangchen, H. Ouli, X. Cengzuo and Z. Yinghuan, The Effect of Impurity lons Molten Salt $\mathrm{KNO}_{3}$ on lon-Exchange and Strengthening of Glass, Journal of NonCrystalline Solid, Vol. 80, P. 313-318, 1986.

[8] V. P. Pukh, L. G. Baikova, M. F. Kireenko, L. V. Tikhonova, T. P. Kazannikova, and A. B. Sinani, Atomic Structure and Strength of Inorganic Glasses, Physis of the Solid State, Vol. 47, No. 5, P. 876-881, 2005.

[9] Y. K. Lee and S. Y. Choi, Characterization and preparation of glass-ceramics in the system $\mathrm{Fe}_{2} \mathrm{O}_{3}-\mathrm{CaO}-\mathrm{SiO}_{2}(\mathrm{I})$, Journal of the Korean Ceramic Society, Vol. 31, No. 6 , P. 629-636, 1994. 